\title{
Web Advertising: Sexual Content on eBay
}

\author{
Michael Giebelhausen, Cornell University \\ Thomas P. Novak, University of California, Riverside
}

Trust is an essential ingredient for commercial success on the Web. "Shopping aggregator" websites such as eBay provide a mechanism for measuring trust in the vendor in the form of online shoppers' positive feedback ratings. This real-world experiment conducted on eBay demonstrates that although coupled with a very high trust rating, the inclusion of an explicitly sexual illustration in shopping aggregator gallery listings dramatically increases auction traffic but in most cases reduces the dollar amount of the winning auction bid, thereby lowering the return to the seller. Traffic increase but lower selling price resulted even for products that could arguably use a sexual appeal (although these products were targeted to women).

\section{Introduction}

Shopping aggregators are websites that allow consumers to simultaneously compare prices across numerous sellers. Examples of shopping aggregators include NextTag.com, Shopzilla.com, Google Product Search, and eBay.com. The majority of online shoppers (59\% in the study by McGann, 2005) prefer to begin their online shopping search at a shopping aggregator website, although they often buy offline if the seller is a "clicks and mortar" retailer.

EBay is perhaps the most influential of all shopping aggregators. As of June 2008 , there were approximately 84.5 million active eBay members buying and selling from an inventory of 112 million products in 39 markets worldwide (eBay.com, 2008). On eBay, a search for a particular product might generate a screen listing of 25 to 200 or so sellers offering the same product at different prices. Presumably in response to these hypercompetitive conditions, some online sellers are employing "shock advertising" tactics in the shopping aggregator category. Shock advertising "attempts to surprise an audience by deliberatively violating norms for societal values and personal ideals" (Dahl et al., 2003, p. 269). On eBay, shoppers will occasionally come across an item where, instead of a typical product 
picture, an unrelated shocking image is featured on the search results screen in the gallery listing. Most commonly, this shock advertising consists of mildly explicit sexual material (see Reichert, 2002).

The use of sexual content in ads, however, may harm consumers' evaluations of the marketer's trustworthiness (see LaTour and Henthorne, 1994). Lack of trust is the most commonly cited barrier to online transactions (Hoffman et al., 1999; Mukherjee and Nath, 2007) and it might therefore be expected that utilizing potentially trust-reducing content such as sex would be an ill-advised tactic for online advertisers.

Most shopping aggregator websites provide shoppers' feedback ratings indicating the trustworthiness of each retailer. Typically, these ratings are the percentage of each retailer's customers who report being "satisfied" with their transactions. This "consensus trust" information is thought to trump other information in influencing online purchase behavior (Benedicktus and Andrews, 2006; Gauri et al., 2008. However, the vast majority of regular sellers on eBay maintain very high feedback scores and thus it is infrequent that a consumer comes across a seller on eBay whose score is not indicative of a high degree of trust.

The research question addressed in the present study is whether an extremely high trust rating allows the online retailer to employ explicit sexual content to gain attention without negative effects on site visitation and the dollar amount of the winning bid (i.e., the selling price of the product).

For those unfamiliar with the eBay website, the following summary may be useful. Essentially, eBay provides a marketplace for used products, as is well known, but mainly for overstocked products offered for clearance by offline retailers. The first listing the visitor sees on eBay is the "gallery" listing, consisting of a small thumbnail picture of the product with a descriptive title located on a "search results" page containing up to 200 other gallery listings. When visitors click on a listing from the gallery they are taken to the full listing. The full listing contains more detailed information, a larger picture or pictures, and additional functions such as the ability to bid on the item. Typically, an Item is listed in auction format and interested buyers place bids over the course of five to seven days. After the transaction is completed, the individual seller who placed the item on eBay, and the buyer, are encouraged to post their satisfaction ratings of the opposite party on the eBay site. The percentage of positive ratings of the vendor, known as "positive feedback," can then be viewed by other eBay members. It should be noted that auctions are not the only type of transaction that occurs on eBay. For example, one popular method of selling is the "buy it now" format. This format more closely resembles the usual non-auction online transaction in that the buyer can immediately purchase the item at a predetermined rather than a bid price. 


\section{Real-World Experiment}

\section{Overview}

Twelve actual eBay auctions were posted where the listed gallery image consisted of either a standard product picture or an unassociated sexual image. Data were collected on the number of visits to each auction and the highest bid placed.

An eBay seller account with an extremely high trust rating (100\% positive feedback on more than 150 transactions over six years) was used to post pairs of auctions of six products. In the "standard" advertising condition of the pair, the gallery thumbnail image consisted of a typical product illustration. In the "sexy" advertising condition of the pair, the gallery listing used an illustration that, while within the guidelines of eBay's acceptable-use policy, contained sexual content as described by Reichert (2002).

\section{Products in the Auctions}

The primary concern when selecting the six products to be sold during this study was their popularity on eBay (as determined by "Andale's What's Hot" report). The reason for this consideration was to ensure there would be sufficiently large numbers of buyers and sellers to generate enough auction visits and bids suitable for statistical analysis.

Two products were selected that might conceivably benefit from a sexual appeal in the gallery listing. One was a "Martha Stewart-style" knitted poncho jacket. The other was a perfume called "212 Sexy." It was realized after these two products were selected that both are mainly bought by women, who may be less responsive to sexual appeals, and so this represents a limitation on the generalizability of the study's findings.

The other four products had no obvious sexual motives for their purchase. Three were fishing hobby products (an interest of one of the authors): a pair of fishing boots, a lightweight fly-fishing reel, and a fly-fishing lure normally retailing for a dollar or less. The fourth general product was a tradable baseball card.

\section{Procedure}

All of the auctions began on a Friday, had a starting price of $\$ .01$, and lasted for five days. The eBay website has a link labeled "seller," whereby feedback ratings can be seen. The six auctions featuring standard product pictures were presented first. The following week, the six auctions were 
repeated, and in these auctions, the standard gallery thumbnail image was substituted by a

(moderately) sexy picture

Measures

The data collected were the number of visits to each auction - presumed to be the same as the number of visitors - and the dollar amount of the winning auction bid.

\section{Results}

Table 1 provides the results for each pair of auctions with the "standard" gallery picture and the "sexy" picture. Overall analyses follow.

Visits

An ANOVA conducted on number of auction visits (i.e., traffic) revealed a significant positive effect of the sexy image over the standard image $\left(M_{\text {standard }}=115.5, M_{\text {sexy }}=369.2 ; F(1,12)=27.51, p=0.021\right)$. The average increase in traffic with sexy images was more than $300 \%$. Each of the general products saw a very large increase of $200 \%$ or more. The two possibly sex-related products, the "Martha Stewart" jacket and the "212 Sexy" brand of perfume, however, showed smaller increases when a sexy picture was used: increases in traffic of $87 \%$ and $10 \%$, respectively.

Winning Bid Amount

An ANOVA on the winning auction bids revealed a nonsignificant effect of sexy image versus standard image (Mstandard $=\$ 62.38, M s e x y=\$ 54.03 ; F(1,12)=0.129, p=0.727)$. On average, the highest bid placed was $16.0 \%$ lower in the sexy picture condition.

The more up-market women's product, the Martha Stewart-style poncho jacket, had its winning bid price reduced by a massive $41 \%$ when advertised with the sexy picture. The overtly sexy product, "212 Sexy" perfume, too, attracted a lower price but the reduction in this case was only $10 \%$.

For the general products, there was one surprising increase in the winning bid price with the sexy image, though it must be realized that this effect could be due to one individual, and probably male, bidder. The other three general products showed small or no price change, with the large percentage decrease for the fly-fishing lure representing a small absolute effect of the sexy appeal. 


\section{Discussion}

Does the presence of an extremely positive feedback or trust score within a shopping aggregator environment allow online retailers to employ controversial ploys to increase visitor traffic without the negative consequence of decreasing consumers' willingness to pay? The present experiment, conducted using actual auctions on eBay, provides a limited test of this broad hypothesis for three reasons. One reason is that the study investigates only the "sex ploy" rather than other well-known devices advertisers use to gain attention such as Benetton's "shocking reality" illustrations in its print ads (which were banned by retailers in the USA.). A second and related limitation is that the two possibly sexrelevant products chosen for the experiment, a designer jacket and a perfume, were both primarily bought by women, and the effect on products targeted toward men is not known. A final limitation is that the experiment was confined to very highly trusted online retailers or sellers, so it is an open question whether a "shoddy" retailer or individual vendor might benefit by employing a sexy appeal for the product.

At best, then, the findings from the present experiment on the eBay shopping aggregator website must be treated as suggestive only. The findings imply that sellers on eBay or other web-auction sites should not use a sexy picture for the gallery listing of their products - of any type. However, this implication warrants further testing.

\section{Table 1}

Results of six pairs of auctions on eBay using a standard versus a sexy illustration in the gallery listing of the product.

\begin{tabular}{|c|c|c|c|c|c|c|c|}
\hline \multirow[b]{2}{*}{ Product } & & \multicolumn{3}{|c|}{ Visitors (number of) } & \multicolumn{3}{|c|}{ Winning bid (\$) } \\
\hline & & Std & Sexy & $\Delta \%$ & Std & Sexy & $\Delta \%$ \\
\hline \multicolumn{8}{|c|}{ Possible sex-compatible } \\
\hline & Women's designer jacket & 201 & 375 & $+87 \%$ & 137.50 & 81.00 & $-41 \%$ \\
\hline & Perfume & 60 & 66 & $+10 \%$ & 34.00 & 30.00 & $-12 \%$ \\
\hline \multicolumn{8}{|l|}{ General } \\
\hline & Fishing boots & 219 & 662 & $+202 \%$ & 86.00 & 77.00 & $-10 \%$ \\
\hline & Fishing-rod flyreel & 103 & 523 & $+408 \%$ & 51.00 & 71.00 & $+39 \%$ \\
\hline & Baseball card & 85 & 376 & $+342 \%$ & 65.00 & 65.02 & $0 \%$ \\
\hline & Fly-fishing lure & 25 & 213 & $+745 \%$ & .57 & .16 & $-72 \%$ \\
\hline
\end{tabular}




\section{References}

Benedicktus RL, Andrews ML. Building trust with consensus information: The effects of valence and sequence direction. J Interact Advert 2006;6(2):17-29.

Dahl DW, Frankenberger KD, Manchanda RV. Does it pay to shock? Reactions to shocking and nonshocking advertising content among university students. J Advert Res 2003;43(3):268-80.

Gauri DK, Bhatnagar A, Rao R. Role of word of mouth in online store loyalty. Commun ACM 2008;51(3):89-91.

Hoffman DL, Novak TP, Peralta M. Building consumer trust online. Commun ACM 1999;42(4):80-5.

LaTour MS, Henthorne TL. Ethical judgments of sexual appeals in print advertising. J Advert 1994;23(3):81-90.

McGann R. Online shoppers prefer aggregators over merchant sites (3/24/2005). Retrieved July 08, 2008, 2008, fromhttp://www.clickz.com/showPage.html? page=3492671.

Mukherjee A, Nath P. Role of electronic trust in online retailing. Eur J Mark 2007;41(9/10):1173-202.

Reichert T. Sex in advertising research: A review of content, effects, and functions of sexual information in consumer advertising. Annu Rev Sex Res 2002;13:241-73. 